\title{
Anabases
}

ANABASES Traditions et réceptions de l'Antiquité

$9 \mid 2009$

Varia

\section{Arnaud HUREL, La France préhistorienne de 1789 à 1941}

\section{Grégory Reimond}

\section{OpenEdition}

\section{Journals}

Édition électronique

URL : http://journals.openedition.org/anabases/585

DOI : 10.4000/anabases.585

ISSN : 2256-9421

\section{Éditeur}

E.R.A.S.M.E.

\section{Édition imprimée}

Date de publication : 1 mars 2009

Pagination : 345-346

ISSN : 1774-4296

\section{Référence électronique}

Grégory Reimond, «Arnaud HuReL, La France préhistorienne de 1789 à 1947 », Anabases [En ligne], 9 | 2009, mis en ligne le 01 juillet 2011, consulté le 22 septembre 2020. URL : http://

journals.openedition.org/anabases/585; DOI : https://doi.org/10.4000/anabases.585

Ce document a été généré automatiquement le 22 septembre 2020.

(c) Anabases 


\title{
Arnaud HUREL, La France préhistorienne de 1789 à 1941
}

\author{
Grégory Reimond
}

\section{RÉFÉRENCE}

Arnaud HUREL, La France préhistorienne de 1789 à 1941, Paris, Éditions du CNRS, 2007, 281 p. 28 euros / ISBN 978-2-271-06600-8.

1 Les historiens de l'archéologie n'ont sans doute pas oublié les remarquables synthèses d'Alain Schnapp (La conquête du passé, Paris, Éditions Carré, 1993) et d'Ève GranAymerich (Les chercheurs de passé (1798-1945), Paris, Éditions du CNRS, 2007): complémentaires par leur approche, ces études nous ont plongés dans le monde des antiquaires, depuis l'Antiquité jusqu'au XIX siècle, et dans celui des premiers archéologues, nous faisant assister à la naissance de l'archéologie moderne. D'une certaine façon, le livre d'Arnaud Hurel, chercheur à l'Institut de paléontologie humaine de Paris, peut être considéré comme le troisième volet de cette saga. Si la période qui retient son attention coïncide avec celle traitée par È. Gran-Aymerich, le thème diffère, rendant ces deux études résolument complémentaires: A. Hurel se penche sur la genèse de la science préhistorique dans une perspective institutionnelle, laissant de côté plusieurs pans de l'histoire interne de la discipline qui ont plus traditionnellement retenu l'attention de ceux qui décidaient d'explorer l'histoire de la discipline (l'histoire des théories, des débats savants, des fouilles, des connaissances n'est pas traitée, si ce n'est au détour d'un paragraphe pour dresser un bref état des lieux à un moment donné). Ainsi, sans être le principal moteur du progrès scientifique, l'institutionnalisation est présentée comme « un accompagnement, parfois décisif, de l'élaboration du savoir scientifique, chacune des étapes de ce processus [faisant office] de marqueur dans une perspective globale où la science est appréhendée comme une activité collective, organisée en des lieux et à travers des institutions » (p. 8). La France préhistorienne vient dès lors apporter une nouvelle pierre à l'édifice de l'histoire de 
l'archéologie dans une perspective sociale, culturelle et politique, approches que privilégient les historiens actuels. Le lecteur aura compris que l'institutionnalisation de la préhistoire, sa professionnalisation et l'émergence d'une législation en matière de protection du patrimoine préhistorique sont au cœur de l'étude d'A. Hurel.

2 Si l'ouvrage s'ouvre sur les débats révolutionnaires quant à la protection d'un patrimoine national dont la notion naît alors (on se souvient des interventions de l'abbé Grégoire devant la Convention, du musée d'Alexandre Lenoir ou du célèbre Mémoire de Pierre Legrand d'Aussy), il se clôt lorsque la France se dote enfin d'une véritable législation sur les fouilles et réorganise les services concernés (loi de 1941, création de la $15^{\mathrm{e}}$ commission consultative du CNRS concernant les fouilles archéologiques en France et à l'étranger). Depuis la loi de mai 1841 jusqu'à l'action du ministre-archéologue Carcopino en passant par la loi de 1887, A. Hurel retrace ainsi la longue et laborieuse genèse d'un corpus juridique destiné à protéger les vestiges matériels, à réglementer la pratique des fouilles sur le terrain, à lutter contre le « commerce » d'antiquités, la détérioration ou la destruction pure et simple des sites. Par là même, nous assistons à un véritable bras de fer dont les protagonistes sont les archéologues professionnels et les amateurs (soutenus par les sociétés savantes et la Société préhistorique française). Longtemps, l'État brille par son absence, se refusant à trancher une question sensible (a-t-on le droit de porter atteinte à la liberté du fouilleur et du scientifique ainsi qu'au sacro-saint droit de propriété ?) qui suscite de virulentes polémiques relayées par la presse locale et nationale. L'" affaire Hauser », minutieusement étudiée par l'auteur, ne constitue qu'une page, peut-être la plus éloquente, de cette histoire.

3 Parallèlement, nous assistons à l'institutionnalisation de la préhistoire en France, longtemps cantonnée aux cercles restreints des sociétés savantes. Depuis la création de la Commission de la topographie des Gaules et du musée des Antiquités nationales de Saint-Germain sous le règne de l'empereur-archéologue (Napoléon III) jusqu'à la fondation de l'Institut de paléontologie humaine (IPH) autour de M. Boule, H. Breuil, H. Obermaier, etc., en passant par la création de l'École d'anthropologie de Broca et des premiers postes universitaires destinés à enseigner la préhistoire, nous voyons naître une véritable science disposant de structures stables et durables, d'organes d'expression, de lieux de sociabilité et de formation.

Cette recension ne saurait prétendre à l'exhaustivité. Nous souhaitons simplement attirer l'attention des lecteurs d'Anabases sur une étude qui est appelée à devenir, pensons-nous, un ouvrage de référence pour l'histoire de l'archéologie préhistorique et des politiques patrimoniales en France. Nous nous permettrons d'exprimer deux réserves : nous regrettons l'absence d'une bibliographie générale, en fin d'ouvrage, qui aurait pu constituer un instrument de travail précieux pour tous ceux qui souhaitent pénétrer plus avant dans l'histoire de l'archéologie française. Au lieu de cela, le lecteur devra se contenter de quelques notes infrapaginales. Ensuite, il nous semble que cette synthèse aurait mérité des annexes utiles au chercheur comme au profane : des cartes situant les sites évoqués, une chronologie, des textes de référence (notamment législatifs), etc. Quelques minces critiques qui n'enlèvent rien à la qualité de cette œuvre qui nous explique comment la préhistoire est devenue science. 


\section{AUTEURS}

GRÉGORY REIMOND

Université de Toulouse (UTM)

g-p.reimond-pandele@hotmail.fr 